\title{
ObituARY
}

\section{Dr. Gordon Guroff (1933-1999)}

Dr. Gordon Guroff, 66, a noted neurochemist and neurobiologist, Deputy Scientific Director of the National Institute of Child Health and Human Development (NICHD) at the National Institutes of Health (NIH), Bethesda, USA, was killed July 9, 1999 in a traffic accident in Moultonboro, NH, USA.

Dr. Guroff was born in Chicago on July 9, 1933. He graduated with a B.S. degree in Chemistry from the University of Illinois in 1954 and received a Master's degree in Biochemistry from Auburn University in 1956. He received his doctorate in Biochemistry from the University of Wisconsin in 1959.

In the same year (1959), Dr. Guroff joined the Laboratory of Clinical Biochemistry, now NIH's National Heart, Blood, and Lung Institute. In 1968, Dr. Guroff was appointed Chief, Section of Intermediary Metabolism. This Section, renamed the Section on Growth Factors in 1983, was created in 1968 as part of the Laboratory of Biomedical Sciences, one of the original laboratories of the NICHD. Dr. Guroff's first NIH appointment was in the National Heart Institute, initially as a post-doctoral fellow and then as an independent investigator, both in the laboratory of Dr. Sidney Udenfriend.

Dr. Guroff had been interested in the general area of the metabolism of the aromatic amino acids, with special emphasis on their involvement in neurobiology. Among Dr. Guroff's publications during that period was one of the first reports showing competition among aromatic amino acids for entry into the brain, an observation that had special relevance to the etiology of phenylketonuria. He also described a phenyalanine hydroxylase, the first to be isolated from a bacterial source. It was his work that led to the elucidation of the hydroxylation-induced migrations, a pathway that became known as the "NIH Shift." He participated in the construction of a credible animal model of phenylketonuria and published the first report of the calcium-activated neutral protease, now known as calpain.

Dr. Guroff's interest in nerve growth factor was kindled during a sabbatical year (1973-1974) spent in the laboratory of Dr. Hans Thoenen, then at the Biozentrum of the University of Basel. In Dr. Thoenen's group, Dr. Guroff participated in studies on the retrograde transport of nerve growth factor and on the purification and utilization of anti-nerve growth factor antibodies. Although much was already known about nerve growth factor at that time, e.g., chemical structure, general properties of the p75 receptor, and nature and significance of retrograde transport, there was virtually no information about the mechanism(s) by which nerve growth factor acts. This important question became

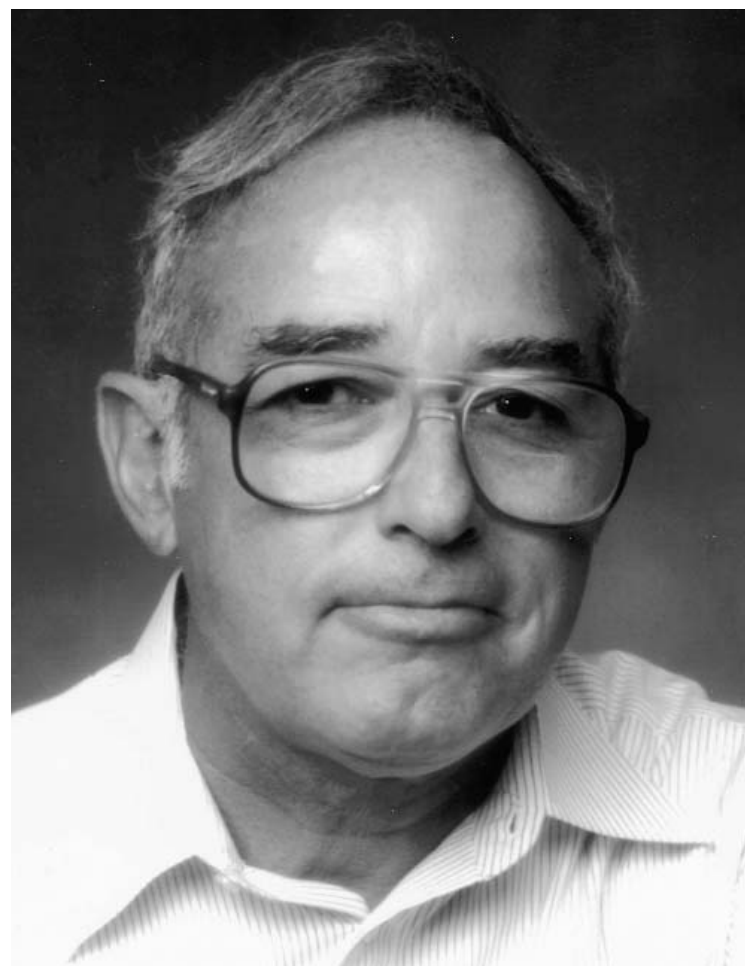


the focus of Dr. Guroff's research. The advent of the PC12 pheochromocytoma cell line a few years later provided the central tool with which these studies have been pursued over the last 25 years.

The initial work in Dr. Guroff's group provided the first report of the involvement of a specific second messenger and the induction of a specific gene by nerve growth factor. His studies also yielded, simultaneously with those of another group, the first reports of a nerve growth factor-stimulated phosphorylation and he published the first description of a cell-free system that captured the effect of nerve growth factor on phosphorylation. His observation on the dual responsivity of PC12 cells to nerve growth factor, a differentiating agent, and epidermal growth factor, a mitogen, illuminated a novel case of receptor cross-talk and provided a facile tool for the exploration of the differences in signal transduction between differentiating agents and mitogens. Indeed, work with this system has given rise to the concept that the temporal aspects of signaling are as important as the nature of the signaling molecules themselves. More recently, Dr. Guroff and his colleagues described the unique actions of the alkaloid kinase inhibitor $\mathrm{K}-252 \mathrm{a}$, a compound that has proven quite valuable as a specific inhibitor of nerve growth factor action, and whose derivatives may well find clinical utility as the first small molecule neurotrophic agents. Within the past 10 years, Dr. Guroff's work moved from the outlines of the phosphorylation pathways activated by nerve growth factor to the functional consequences of some of these phosphorylations. For example, he explored the effects of specific phosphorylations of the transcription factor NGFI-B on its ability to bind to and activate its response element. He investigated the ability of nerve grow th factor to stimulate calcium uptake into its target cells and the role of phosphorylation in that stimulation. He was concerned with the role of phosphorylation on the translation process, specifically with the changes that occur upon nerve growth factor-altered phosphorylation of S6 and EF-2, important aspects in molecular neurobiology.

Dr. Guroff was the author of the textbook Molecular Neurobiology, and he published nearly 200 papers in professional journals. He was the editor of three volumes in a series on growth and maturation factors and the editor of another book on oncogenes, genes, and growth factors. He was a member of the editorial advisory boards of a number of professional journals and was also a lecturer in biochemistry at George Washington University, Washington, DC.
In the course of his career, Dr. Guroff trained, in his program at NIH, more than 100 post-doctoral fellows from around the world. Many of them have gone on to responsible positions in research, primarily in the growth factor field, and have remained associated with Dr. Guroff as collaborators. His work has attracted physicians interested in neurology and pediatrics, and postdoctoral students with degrees in pharmacology, biochemistry, biology, and molecular biology. Senior visitors from Japan, Yugoslavia, Israel, Russia, Armenia, and Italy have chosen to pursue their work in his Section, providing guidance and stimulation for the junior scientists. All have found some aspect of the multidimensional research problem that was consistent with their scientific and professional interests. Numerous collaborations have resulted from Dr. Guroff's willingness to share resources and information with others at the $\mathrm{NIH}$, in the United States, and abroad. His Section has become the sponsor and focal point for the yearly speaker series known throughout the NIH and international community as the NGF Club.

Dr. Guroff is survived by his wife, Marjorie RobertGuroff, and their two children, Sarah and Robert, as well as three children, Peter, Margaret, and Steve from his first marriage, his mother, his brother, and four grandchildren. His many colleagues and trainees will long remember him not only for his scientific contributions to neuroscience and his deep intellectual insights, but also for his gentle guidance, friendship, and humble humanity.

\section{Dr. Philip Lazarovici Dept. of Pharmacology and Experimental Therapeutics School of Pharmacy Faculty of Medicine The Hebrew University of Jerusalem Jerusalem, Israel}

\section{Personal Note}

Dr. Gordon Guroff was both a friend and a scientist in his function as Deputy Scientific Director of the National Institute of Child Health and Human Development. He was a pillar of the Institute, and he is and will be missed.

Prof. Illana Gozes Editor 